\title{
Mapping Sea Water Surface in Persian Gulf, Oil Spill Detection Using Sentinal-1 Images
}

\author{
M. Majidi Nezhad ${ }^{1}$, D. Groppi ${ }^{1}$, P. Marzialetti ${ }^{2}$, G. Piras ${ }^{1}$, G. Laneve ${ }^{2}$ \\ ${ }^{1}$ Department of Astronautics, Electrical and Energy Engineering (DIAEE), Sapienza University of Rome \\ Rome, Italy \\ meysam.majidinezhad@uniroma1.it; daniele.groppi@uniroma1.it; giuseppe.piras@uniroma1.it \\ ${ }^{2}$ School of Aerospace Engineering, Sapienza University of Rome, \\ Rome, Italy \\ pablo.marzialetti@uniroma1.it; giovanni.laneve@uniroma1.it
}

\begin{abstract}
The present study investigates an oil spill event in the Al Khafji region using Sentinel 1 SAR images. Al Khafji is on the border between Saudi Arabia and Kuwait in the Persian Gulf and it is considered a neutral zone. Al Khafji region has the potential to produce more than 470,000 barrels of oil per day (Mbbl/d).

Methods based on multi sensor satellite images (Sentinel-2, Landsat 8, Terra, Cosmo_SkyMed, RADARSAT, etc.) analysis have been developed for detecting oil slicks from known natural seeps as well as oil spill events. In this paper, one of these methods is applied to Sentinel 1 images of a known area of natural oil outflow and of a recent oil spill event in Al Khafji zone. The Synthetic Aperture Radar (SAR) is recognized as the most important remote sensing tool for sea and ocean waters oil spill monitoring, recording, documentation and dissemination. Oil spills have been detected and characterized by using the SAR images over the Persian Gulf. In particular, this paper discusses oil spills detection in the Persian Gulf assessed by using Sentinel 1 (SAR) images. Results showed the suitability of the VV polarization of the Sentinel-1 for detecting oil-spills as well as the reduced utility of the VH polarization in this context.
\end{abstract}

Keywords: Sea And Ocean Monitoring, Oil Spill, Sentinel 1, Synthetic Aperture Radar (SAR).

\section{Introduction}

The fast growth of population and industrial activity is causing a proportionate increase of energy consumption all over the world and the risk of pollution to oceans, land, air, in one word to the environment and the living beings has become inevitable [1]. Energy consumption still heavily relies on fossil fuels [2-3] but the transition towards a Renewable Energy Sources (RES) based system is continuing stronger every year [4-5]. As a matter of fact, in 2016, solar PV systems accounted for $47 \%$ of the total newly installed power capacity, followed by wind power with $34 \%$ and hydropower at $15.5 \%$ [6]. Research is now moving towards the concept of Smart Energy Systems (SES) [7] thus studying integrated systems aiming at coupling and improving the main energy sector [8-9] on the other hand, the focus is also increasing in the field of air and sea pollution evaluation [10-12] environment sensitivity [13-15] and risk assessment, especially those due to oil spill events [16-20].

In this context, the use of multi sensor satellites images has become a common practice to monitor environmental pollution and in particular to detect oil spill occurrences [21]. Methods based on the analysis of multi sensor satellite images (e.g. Sentinel-2, Landsat [22], Terra, Cosmo_SkyMed, RADARSAT, etc.) have been developed for detecting oil spills from known natural seeps as well as for extraordinary human related oil spill events.

Today, the detection approaches for monitoring and recording oil spill events are usually divided into two types depending on the exploitation of optical or SAR (Synthetic Aperture Radar) satellite sensors [23-24]. The Synthetic Aperture Radar satellites have been rapidly developing in the last decade since the ESA ERS satellites launched in 1991 [25] and it became an effective tool in oil spill monitoring. That is mainly due to its capability to offer synoptic data of wide areas and imaging ability in all weather conditions during day and night times [26-27]. Therefore, SAR sensors represent today an effective and efficient tool to monitor oil spill on global seas and ocean waters [25-28]. European Space Agency (ESA), has recently launched in orbit, as part of its ambitious Copernicus Earth Observation program, the European Radar Observatory (Sentinel-1) [29], for providing routinely, 24 hours, all-weather coverage of land and ocean. Free and open Sentinel-1 data 
access is provided. The unique data availability performance of the Sentinel-1 routine operations makes the mission particularly suitable for, apart others, emergency response support and marine surveillance [29].

Oil spills are environmental disasters that most often lead to negative important factors on aquaculture, sea grasses, coral reefs, desalination plants, fish industrial, seashell and crab farms, and tourism activities [30]. Many studies on oil spills detection and analysis have been conducted in most of the main seas and oceans with different satellites and methods: Li [30], Simecek-Beatty [31], Lardner [32], Guo [33], Mera [34], Romero [35].

The aim of the paper is to analyse oil spills occurred in the Persian Gulf by using SAR sensor images. In particular, one oil spill event was investigated using Sentinel 1 (SAR) images in the Al Khafji region between Kuwait and Saudi Arabia. This study proposes an automatic image processing technique specifically aimed at detecting oil spill events.

\section{Site Description}

Persian Gulf covers an area of about 251,000 square kilometres and it is connected to the Gulf of Oman in the east by the Strait of Hormuz. Its length is around 989 kilometres and its borders includes Iran, Saudi Arabia, Kuwait, Qatar, Emirates, Bahrain, Oman and Iraq.

Ras Al Khafji or Al Khafji (Fig 1) is an important area for oil extraction that has been shared between Kuwait and Saudi Arabia. In fact, it is a considered as neutral zone; due to this peculiar characteristic in recent history it has been one of the main reason for the Persian Gulf War in the beginning of the 90', the Battle of Khafji. It is on the border between Saudi Arabia and Kuwait in the Persian Gulf, precisely its coordinates are $28^{\circ} 25^{\prime} \mathrm{N}$ and $48^{\circ} 30^{\prime} \mathrm{E}$.

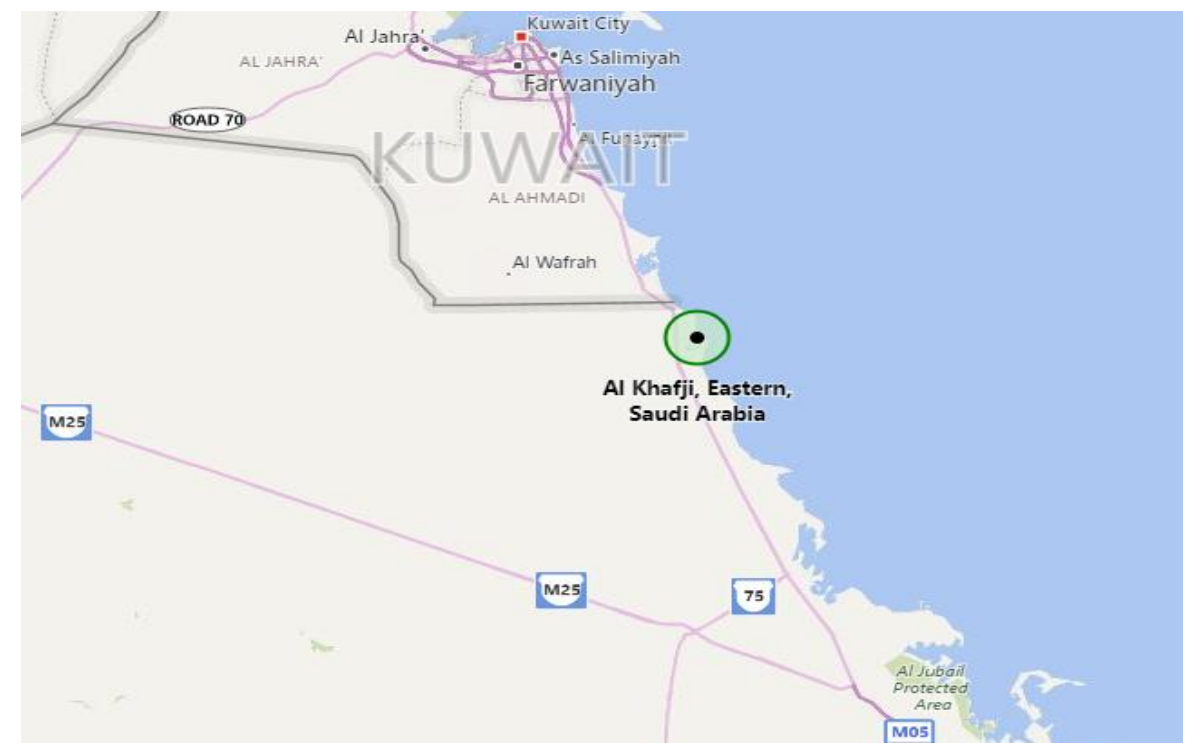

Fig. 1: The Persian Gulf study area (green circle).

\section{Method}

This paper studied the oil spill happened in Al Khafji in July 2017. The Sentinel 1 images have been downloaded from https://scihub.copernicus.eu. The satellite has been designed and developed by the European Space Agency (ESA) and is part of a series of satellite missions called Sentinels (Sentinel 1, Sentinel 2, Sentinel 3, Sentinel 4, Sentinel 5, Sentinel 6) which will be launched in the framework of the Copernicus Earth Observation programme. The Sentinel-1 SAR sensor supports two different operation mode: single polarisation $(\mathrm{HH}$ or $\mathrm{VV})$ and dual polarisation $(\mathrm{HH}+\mathrm{HV}$ or $\mathrm{VV}+\mathrm{VH})($ https://sentinel.esa.int).

\subsection{Datasets}

In this study one type of image has been used, namely Sentinel 1A, with two diferrent Polarization (VH and VV Polarization), those are summarised in Table 1. 
Table 1: List of the Sentinel 1 satellite images used in this study.

\begin{tabular}{|c|c|c|c|}
\hline Geographic Area & Date & Satellite & \multicolumn{1}{|c|}{ Image } \\
\hline Al Khafji & 2017.07 .17 & S1A & IW_GRDH_1SDV_017505_01D444_2D47 \\
\hline Al Khafji & 2017.07 .29 & S1A & IW_GRDH_1SDV_017680_01D9A0_A6EA \\
\hline
\end{tabular}

\subsection{VH and VV Polarization}

Studies about oil spills proved that X-band radar performs better than others bands radar (e.g. C or L) as well as vertical (VV) polarization is better than horizontal (HH) or cross-polarization (HV) (Table 2). Typically, transmission and reception are in the same polarity polarization, i.e. VV or HH. But, there are actually 4 poles available: $\mathrm{HH}, \mathrm{VV}, \mathrm{HV}$ and VH. Use of all four of these is designated as quadrupole (or full-pole). Many studies on oil spill detection monitoring and characterization have been conducted in most of the main sea and ocean waters with polarized SAR satellites images: Skrunes [36], Banks [37], Velotto [38], Marghany [39], Silva [40], Zhang [41].

Table 2: Hypothetical radar backscatter values at $\mathrm{HV}$ or VH and VV polarization for oil spills detection (www.nrcan.gc.ca).

\begin{tabular}{|c|c|c|c|c|}
\hline Polarization & Water & Oil-covered water & SAR noise floor & contrast \\
\hline VV & $-20 \mathrm{db}$ & $-28 \mathrm{db}$ & $-30 \mathrm{db}$ & $8 \mathrm{db}$ \\
\hline HV or VH & $-30 \mathrm{db}$ & $-38 \mathrm{db}$ & $-30 \mathrm{db}$ & $0 \mathrm{db}$ \\
\hline
\end{tabular}

\section{Results}

The Al Khafji oil spill in the Persian Gulf is shown in (Fig 2 and 3), the big slick of oil can be seen in the Sentinel 1 image collected in July 2017.

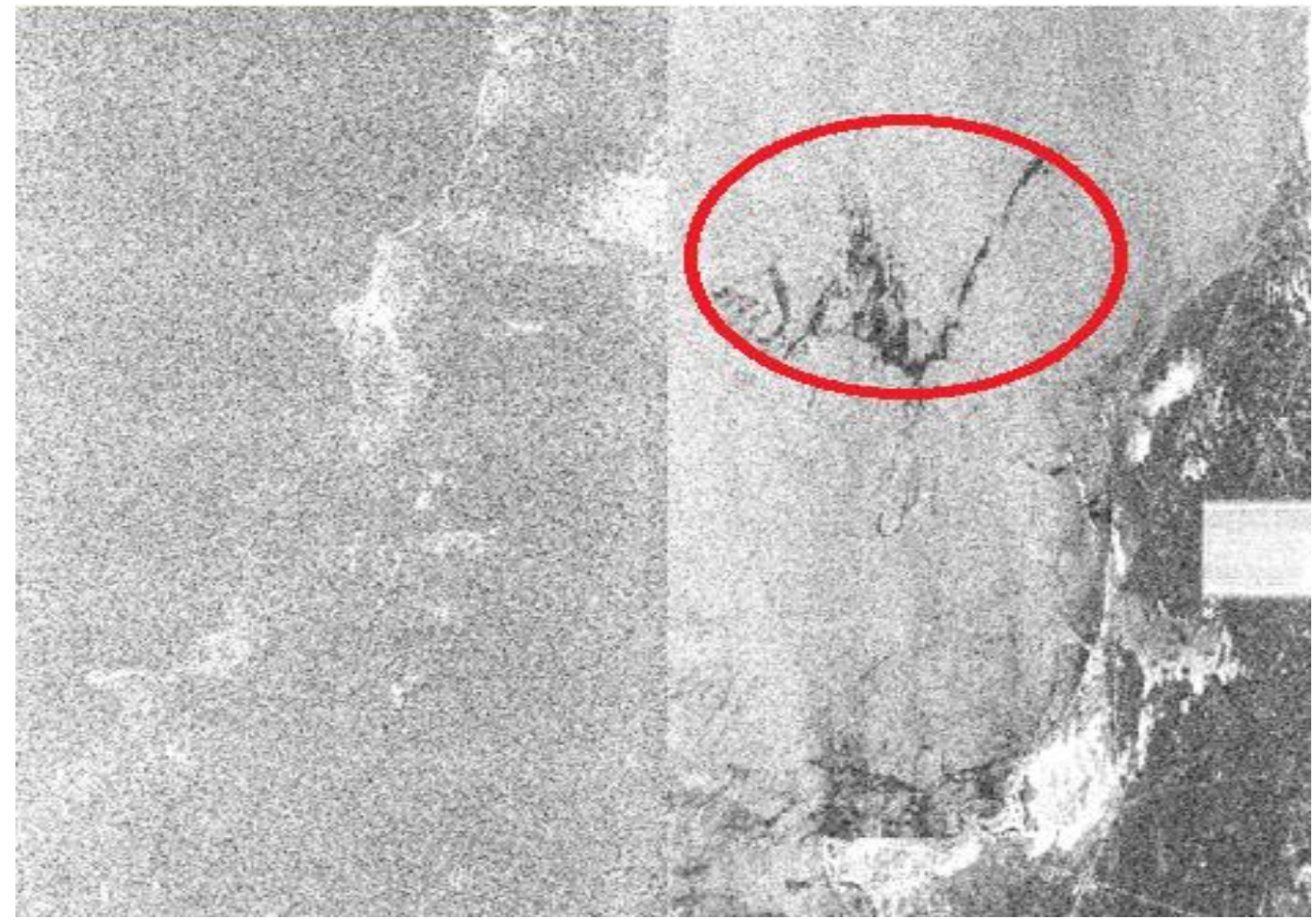

Fig. 2: Sentinel 1 (SAR) images acquired on the 2017.07.17 Al Khafji region. For analysing this image the SNAP software has been used. The amplitude VH-db (left) and amplitude VV-db (right) images are shown. The signals collected in two different polarization VH and VV shown for comparison only. The oil spill areas are outlined with a red circle. 


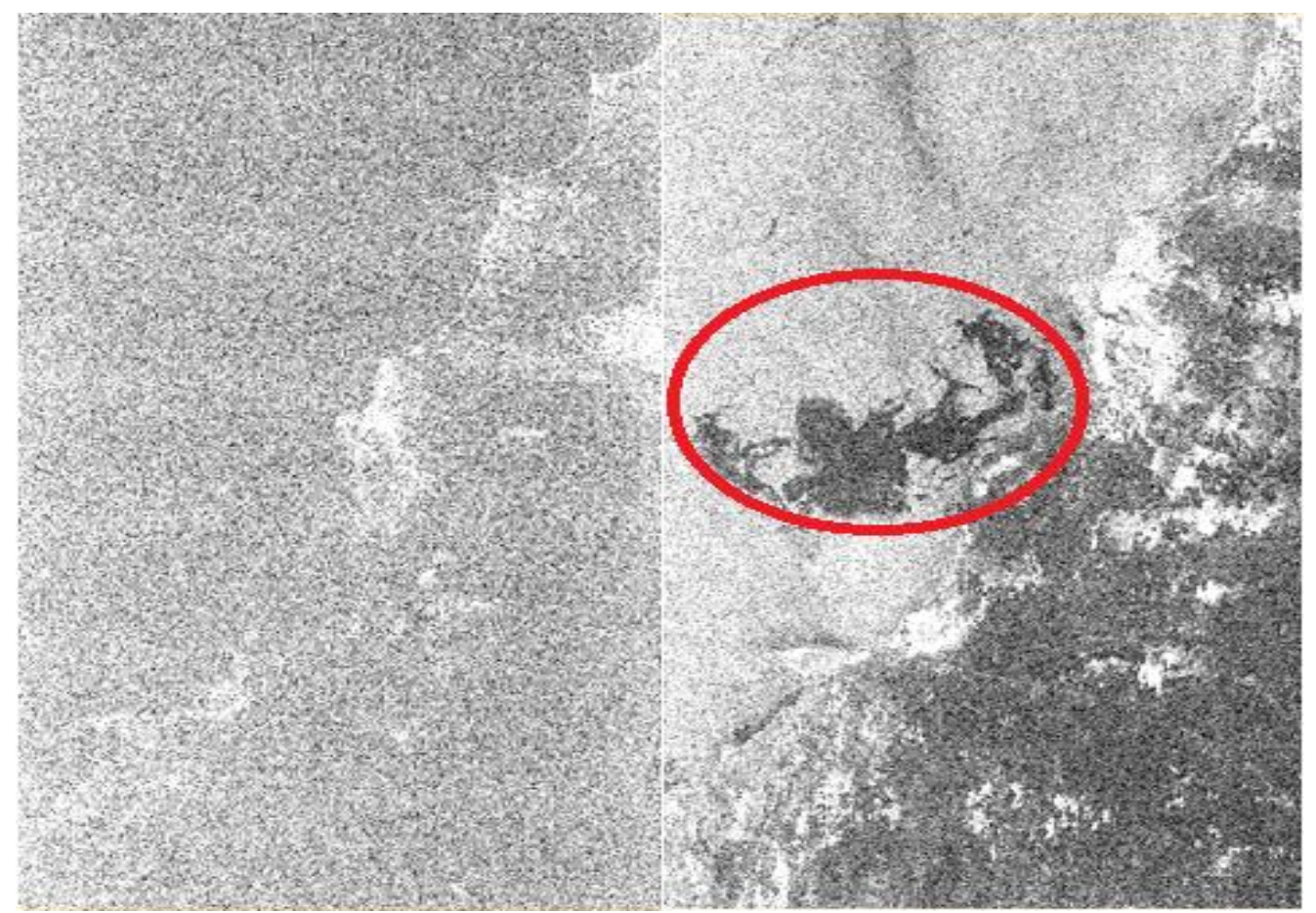

Fig. 3: Sentinel 1(SAR) images for 2017.07.29 around the Al Khafji region. For analysing this image the SNAP software has been used. The amplitude VH-db (left) and amplitude -VV-db (right) images are shown. Fig 3 shows the VH-VV polarization only for comparison. The oil spill areas are outlined with a red circle.

This paper focus on the use of VV polarization for oil spill detection and monitoring in sea and ocean waters. Fig. 2 and 3 show that vertical polarization (VV) is preferable to cross-polarization ( $\mathrm{HV}$ and $\mathrm{VH}$ ) for detecting oil spills. In fact, the presence of oil on the sea surface has a very little effect on VH or HV polarized images with respect to its effect on the VV polarized image, therefore $\mathrm{HV}(\mathrm{VH})$ polarization are less useful for detecting oil spills.

Sentinel-1 is not only the most important remote sensing tool for sea and ocean waters oil spill detection and monitoring but also the VV polarization gives better results than the other polarizations for detection and monitoring oil spill scenarios in marine environment. In this study, $\mathrm{VH}$ and VV polarizations have been tested for detecting oil-spills and results showed using VV polarization leads to greater accuracy. It is very clear the VV image is better for detecting oil spills and also can be used to difference between the VH and VV polarization, for detection oil spills in sea and ocean surface area.

The main reason for successfully by VV polarization for detect the oil spills, sensitive to the roughness of the sea and ocean waters surface. Two important factors in this case: wind speed and wind direction. imagery acquired at VV polarization by SAR satellite is the very sensitive to wind speed variability.

Not only suppression of the capillary sea and ocean water waves by oil spills reduces the surface roughness resulting in less radar emissivity, backscatter and darker area in images SAR satellites, but also detection of oil spills has been shown to be best in moderate wind speed between $3-10 \mathrm{~m} / \mathrm{s}$ (http://www.nrcan.gc.ca).

\section{Conclusion}

In this paper reported the analysis by, high-resolution C-band dual-polarization VV/VH from Sentinel-1A satellite to detect oil spill in the Al Khafji zone in the Persian Gulf in July 2017. SNAP software has been used on Sentinel 1 imagery in order to detect oil spills. The software can be applied to Sentinel 1 images. It has been tested that the presence of oil on the sea surface has a very little effect on VH or HV polarized images with respect to its effect on the VV polarized image, therefore $\mathrm{HV}(\mathrm{VH})$ polarization are less useful for detecting oil spills. Using VV Polarization, the oil spill in sea water surface to the have been successfully detected. The preliminary results are considered successful and consistent, with a high degree of applicability to other Sentinel 1 satellite images satellite measurements prove to be an first important tool for oil detection and monitoring. The next steps will be to use GNOME software to simulate oil spill trend 


\section{References}

[1] M. J. Ha, "Modeling for the allocation of oil spill recovery capacity considering environmental and economic factors," Mar. Pollut. Bull., vol. 126, no. September 2017, pp. 184-190, 2018.

[2] F. Calise, M. D. D'Accadia, C. Barletta, V. Battaglia, A. Pfeifer, and N. Duic, "Detailed modelling of the deep decarbonisation scenarios with demand response technologies in the heating and cooling sector: A case study for Italy," Energies, vol. 10, no. 10, 2017.

[3] M. Noussan, R. Roberto, and B. Nastasi, "Performance Indicators of Electricity Generation at Country Level-The Case of Italy," Energies, vol. 11, no. 3, p. 650, 2018.

[4] Ren21, Renewables 2017 global status report 2017. 2017.

[5] D. F. Dominković, I. Bačeković, B. Ćosić, G. Krajačić, T. Pukšec, N. Duić, N. Markovska, "Zero carbon energy system of South East Europe in 2050," Appl. Energy, vol. 184, pp. 1517-1528, 2016.

[6] I. Bačeković and P. A. Østergaard, "Local smart energy systems and cross-system integration," Energy, vol. 151, pp. 812-825, 2018.

[7] H. Lund, "Renewable heating strategies and their consequences for storage and grid infrastructures comparing a smart grid to a smart energy systems approach," Energy, vol. 151, pp. 94-102, 2018.

[8] G. Lo Basso, B. Nastasi, F. Salata, and I. Golasi, "Energy retrofitting of residential buildings - How to couple Combined Heat and Power (CHP) and Heat Pump (HP) for thermal management and off-design operation," Energy Build., vol. 151, no. July, pp. 293-305, 2017.

[9] B. Castellani et al., "Experimental investigation on $\mathrm{CO} 2$ methanation process for solar energy storage compared to CO2-based methanol synthesis," Energies, vol. 10, no. 7, pp. 1-13, 2017.

[10] D. Astiaso Garcia, F. Cumo, F. Gugliermetti, and F. Rosa, "Hazardous and noxious substances (HNS) risk assessment along the italian coastline," Chem. Eng. Trans., vol. 32, pp. 115-120, 2013.

[11] D. Astiaso Garcia, F. Cinquepalmi, and F. Cumo, "Air quality in Italian small harbours: A proposed assessment methodology," Rend. Lincei, vol. 24, no. 4, pp. 309-318, 2013.

[12] A. Baysal and S. Akman, "Assessment of chromium and nickel levels in surface sea waters and sediments from industrial marine area in Tuzla Aydinli Bay, Istanbul Turkey," Mar. Pollut. Bull., vol. 130, no. December 2017, pp. 293-298, 2018.

[13] M. Marignani et al., "Identification and prioritization of areas with high environmental risk in Mediterranean coastal areas: A flexible approach," Sci. Total Environ., vol. 590-591, no. May, pp. 566-578, 2017.

[14] G. Harik et al., "Implications of adopting a biodiversity-based vulnerability index versus a shoreline environmental sensitivity index on management and policy planning along coastal areas," J. Environ. Manage., vol. 187, pp. 187200, 2017.

[15] F. Gugliermetti, F. Cinquepalmi, and D. Astiaso Garcia, "The use of environmental sensitivity indices (ESI) maps for the evaluation of oil spill risk in Mediterranean coastlines and coastal waters," WIT Trans. Ecol. Environ., vol. 102, pp. 593-600, 2007.

[16] A. Al Shami, G. Harik, I. Alameddine, D. Bruschi, D. A. Garcia, and M. El-Fadel, "Risk assessment of oil spills along the Mediterranean coast: A sensitivity analysis of the choice of hazard quantification," Sci. Total Environ., vol. 574, pp. 234-245, 2017.

[17] D. Astiaso Garcia, D. Bruschi, F. Cumo, and F. Gugliermetti, "The Oil Spill Hazard Index (OSHI) elaboration. An oil spill hazard assessment concerning Italian hydrocarbons maritime traffic," Ocean Coast. Manag., vol. 80, pp. 1-11, 2013.

[18] L. De Santoli, F. Cumo, D. Astiaso Garcia, and D. Bruschi, "Coastal and marine impact assessment for the development of an oil spill contingency plan: The case study of the east coast of Sicily," WIT Trans. Ecol. Environ., vol. 149, pp. 285-296, 2011.

[19] M. M. Nezhad, D. Groppi, G. Laneve, P. Marzialetti, and G. Piras, "Oil Spill Detection Analyzing ' Sentinel 2' Satellite Images: A Persian Gulf Case Study,” pp. 1-8, 2018. DOI:1011159/awapt18.134.

[20] F. Cumo, F. Cinquepalmi, and D. Astiaso Garcia, "Data gathering guidelines for the mapping of environmental sensitivity to oil spill of the Italian coastlines," WIT Trans. Built Environ., vol. 99, pp. 119-125, 2008.

[21] M. Fingas and C. Brown, "Review of oil spill remote sensing," Mar. Pollut. Bull., vol. 83, no. 1, pp. 9-23, 2014.

[22] Q. Xing, L. Li, M. Lou, L. Bing, R. Zhao, and Z. Li, "Observation of Oil Spills through Landsat Thermal Infrared 
Imagery: A Case of Deepwater Horizon," Aquat. Procedia, vol. 3, pp. 151-156, 2015.

[23] J. Fan, F. Zhang, D. Zhao, and J. Wang, "Oil Spill Monitoring Based on SAR Remote Sensing Imagery," Aquat. Procedia, vol. 3, pp. 112-118, 2015.

[24] X. Li, C. Li, Z. Yang, and W. Pichel, "SAR imaging of ocean surface oil seep trajectories induced by near inertial oscillation," Remote Sens. Environ., vol. 130, pp. 182-187, 2013.

[25] W. Tian, X. Bian, Y. Shao, and Z. Zhang, "On the Detection of Oil Spill with China's HJ-1C SAR Image," Aquat. Procedia, vol. 3, pp. 144-150, 2015.

[26] S. Sun et al., "Oil slick morphology derived from AVIRIS measurements of the Deepwater Horizon oil spill: Implications for spatial resolution requirements of remote sensors," Mar. Pollut. Bull., vol. 103, no. 1-2, pp. 276-285, 2016.

[27] W. Alpers, B. Holt, and K. Zeng, "Oil spill detection by imaging radars: Challenges and pitfalls," Int. Geosci. Remote Sens. Symp., vol. 2017-July, no. October 2016, pp. 1522-1525, 2017.

[28] R. Jatiault, D. Dhont, L. Loncke, and D. Dubucq, "Monitoring of natural oil seepage in the Lower Congo Basin using SAR observations," Remote Sens. Environ., vol. 191, pp. 258-272, 2017.

[29] R. Torres et al., "GMES Sentinel-1 mission," Remote Sens. Environ., vol. 120, pp. 9-24, 2012.

[30] P. Li, Q. Cai, W. Lin, B. Chen, and B. Zhang, "Offshore oil spill response practices and emerging challenges," Mar. Pollut. Bull., vol. 110, no. 1, pp. 6-27, 2016.

[31] D. Simecek-Beatty and W. J. Lehr, "Extended oil spill spreading with Langmuir circulation," Mar. Pollut. Bull., vol. 122, no. 1-2, pp. 226-235, 2017.

[32] T. M. Alves, E. Kokinou, G. Zodiatis, R. Lardner, C. Panagiotakis, and H. Radhakrishnan, "Modelling of oil spills in confined maritime basins: The case for early response in the Eastern Mediterranean Sea," Environ. Pollut., vol. 206, pp. 390-399, 2015.

[33] J. Guo, Y. He, X. Long, C. Hou, and X. Liu, "Repair Wind Field of Oil Spill Regional Using SAR Data," Aquat. Procedia, vol. 3, pp. 103-111, 2015.

[34] D. Mera, J. M. Cotos, J. Varela-Pet, P. G. Rodríguez, and A. Caro, “Automatic decision support system based on SAR data for oil spill detection," Comput. Geosci., vol. 72, pp. 184-191, 2014.

[35] I. C. Romero et al., "Large-scale deposition of weathered oil in the Gulf of Mexico following a deep-water oil spill," Environ. Pollut., vol. 228, pp. 179-189, 2017.

[36] S. Skrunes, C. Brekke, C. E. Jones, and B. Holt, "A Multisensor Comparison of Experimental Oil Spills in Polarimetric SAR for High Wind Conditions," IEEE J. Sel. Top. Appl. Earth Obs. Remote Sens., vol. PP, no. 99, pp. 1-14, 2016.

[37] S. Banks et al., "Contributions of actual and simulated satellite SAR data for substrate type differentiation and shoreline mapping in the Canadian arctic," Remote Sens., vol. 9, no. 12, 2017.

[38] D. Velotto, M. Migliaccio, F. Nunziata, S. Lehner, and C. Direziale, "Dual-Polarized Terrasar-X Data For Oil-Spill," no. 1, pp. 1-11.

[39] M. Marghany and J. Van Genderen, "Entropy algorithm for automatic detection of oil spill from radarsat-2 SAR data," IOP Conf. Ser. Earth Environ. Sci., vol. 18, no. 1, 2014.

[40] A. C. Silva, W. G. De Branco, D. Penha, L. T. Calvoso, T. R. Sarmento, and M. F. Pascual, "Semi-automatic Oil Spill Detection in Sentinel- 1 SAR Images at Brazil 's Coast," no. c, pp. 1-5, 2017.

[41] B. Zhang, W. Perrie, X. Li, and W. G. Pichel, "Mapping sea surface oil slicks using RADARSAT-2 quad-polarization SAR image," Geophys. Res. Lett., vol. 38, no. 10, 2011. 